\title{
EXPERIMENTAL STUDY THE EFFECT ANGLE OF BLADE ON THE ELECTRICAL POWER OUTPUT OF PROPELLER PICOHYDRO TURBINE
}

\author{
Abdullah Shalih ${ }^{1}$, Purwadi Joko Widodo ${ }^{1}$, Dwi Aries Himawanto ${ }^{1}$ \\ ${ }^{1}$ Mechanical Engineering - Universitas Sebelas Maret \\ Email address: Shalihab002@gmail.com
}

\section{Keywords :}

Pico-hydro

Propeller turbine

Horizontal flow

Angle of blade

Electrical power

\begin{abstract}
:
This study aimed to analyze the effect of angle of blade on the horizontal flow to the performance of the propeller water turbine. The experiments were performed using several test parameters including the angle of blade on the variation mass flow rate of water. With potential head 2 meters and variated turbine blade angle to achieved optimal power generated. The result showed that the variation of angle of blade with $30^{\circ}$ angles and $11.6 \mathrm{l} / \mathrm{s}$ mass flow rate of water was the best variation to improve the performance of the propeller water turbine. The best variation can generated $32 \mathrm{Watt}$ of electric power.
\end{abstract}

\section{INTRODUCTION}

The availability of electrical energy in Indonesia is increasingly diminishing because the number of Indonesians is increasing so that the users of electricity are also increasing. In general, the potential for renewable energy, especially micro hydro in Indonesia is very good, which has a power of about $480 \mathrm{~W}$, but only $60 \mathrm{MW}$ can be utilized and the remaining $420 \mathrm{MW}$ has not been able to be utilized properly [1].

One of the alternative efforts to utilize water energy as an energy source is by creating a picohydro electric power plant where hydropower is used as a driving force for electricity generation. Pico-hydro has advantages in terms of size in terms of cost and simplicity to approach design, planning, and installation compared to large-scale hydropower plants [2]. Pico-hydro uses high falls below $10 \mathrm{~m}$ with the ability to produce electricity below 5 kilowatt [3].

In pico-hydro, modern turbines are widely used, namely Pelton, Francis or propeller turbines. Turbine propeller is a turbine that is often used because the turbine propeller is a reaction turbine that is able to produce electricity with low and high flow rates falling below $5 \mathrm{~m}$ and many are located downstream with very low falling height [4].

Research to improve the efficiency of water turbine is done by adding a bulb body to the water turbine component. Bulb body is placed before the propeller, with a function to increase the speed of fluid flow and to direct the flow of fluid so that it directly affects the propeller. The research was carried out with the simulation method with the parameters examined were the blade opening angle [5].
The selection of the type of turbine can be calculated by considering the specific parameters that affect the turbine operating system. This parameter is the factor of the height of the waterfall (Net Head) and the flow rate of the water [6].

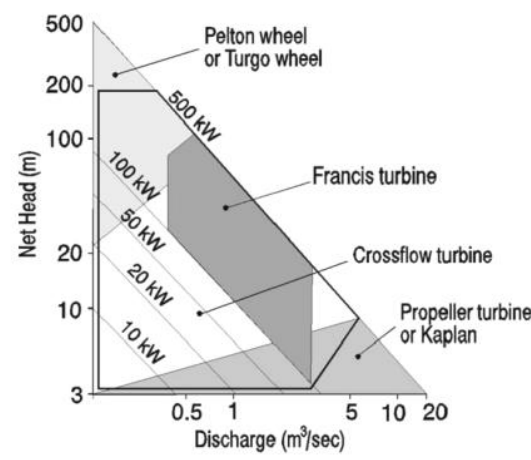

Figure 1. Characteristics and applications of turbines (H vs. Q)

From the picture 1. turbine type propeller is the type of turbine that is most suitable for the piping system. The propeller turbine can effectively operate on a mass flow range from low to high and at low (Net Head) heights.

The aim of this research is to get the best blade angle on the horizontal flow propeller turbine. Schematic testing as shown in Figure 2, the flow of water fluid in the test is a horizontal flow with a head of $2 \mathrm{~m}$. Whereas for testing discharge varies by 5.61 / s; 7.41 / s; 8.81 / s; 10.01 / s; 11.61 / s. Test parameters in the form of mechanical power and electrical power. 


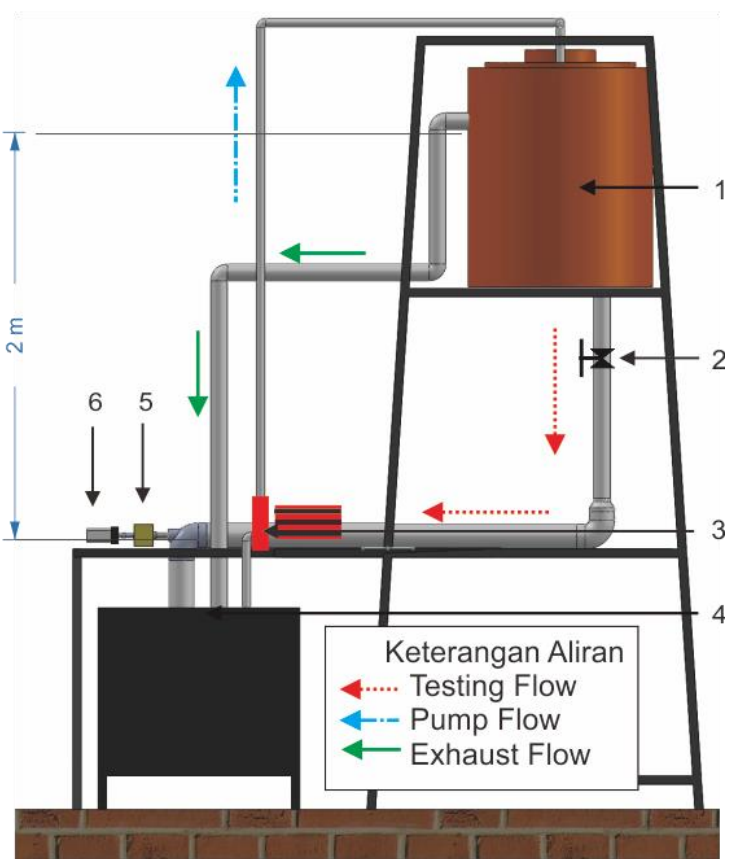

Figure 2. Testing Tool Scheme

1. Upper reservoir

2. Opening valve

3. Pump

4. Lower reservoir

5. Gearbox

6. Generator

Figures 2 shows the testing scheme of the propeller turbine. The test flow used is horizontal flow, it aims to equalize the flow in the river. Pump flow in this test aims to drain water into the reservoir to fill the water lost during the test. The exhaust flow aims to keep the head fixed at a height of $2 \mathrm{~m}$. The valve is used to adjust the opening in the test, the valve opening is varied at 5 openings. The shaft of the turbine is connected to the ager box to increase the rotational speed to match the effective rotating speed of the generator.



Figure 3. Testing of generators

Figures 3 shows the electrical circuit diagram of the generator. The generator used in this study is a Yuskawa Electric 3 phase generator with a maximum power of 170 watts with an optimum rotational speed of $2500 \mathrm{rpm}$ and a torque of $0.4 \mathrm{Nm}$. Testing the electrical output power of the generator is done by calculating the voltage and current generated from the generator. To get the value of voltage and current strength, the electric output of the generator is connected to a $12 \mathrm{~V}$ LED light connected to a multimeter as shown in Figure 3 . The electrical voltage and electric current are obtained from the reading of the multimeter. Multimeters are installed in series to get the electric current value (A), while to get the voltage value $(\mathrm{V})$, the multimeter is installed in parallel[7].

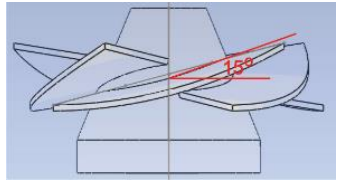

Blade angle $15^{\circ}$

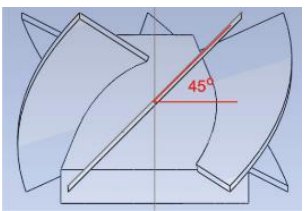

Blade angle $45^{\circ}$

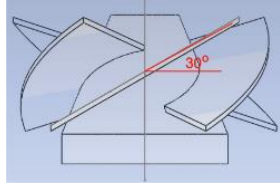

Blade angle $30^{\circ}$

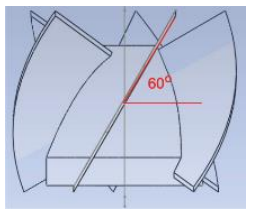

Blade angle $60^{\circ}$



Blade angle $75^{\circ}$

Figure 4. Test specimens

Figure 4. Addressing the shape of the propeller turbine used in the study. Turbine propeller in blade angle variation. The blade angle used are $15^{\circ}, 30^{\circ}, 45^{\circ}, 60^{\circ}$, and $75^{\circ}$. The blade angle is measured from the turbine blade to the horizontal line.

\section{RESULT AND DISCUSSION}

\section{Hydrostatic Power}

Water power is the ability of water flow as a force to pound turbine blades to rotate turbines. Water power $(\mathrm{Ph})$ is a function of water density, gravitational force, falling water level and fluid flow discharge. The head is measured from the level of the upper water surface of the tank until the turbine shaft is 2 meters. Water has power as potential energy that is dropped at a height of 2 meters with a certain fluid flow discharge $\mathrm{Q}$ to pound the turbine as an axial force. The following equation can be used to obtain water power.

$$
p_{H}=Q \cdot \rho \cdot g \cdot h
$$

From the equation above obtained the value of water power generated to drive the turbine rotor 
with a variety of fluid discharge. Graph of hydrostatic power input is shown in Figure 5.

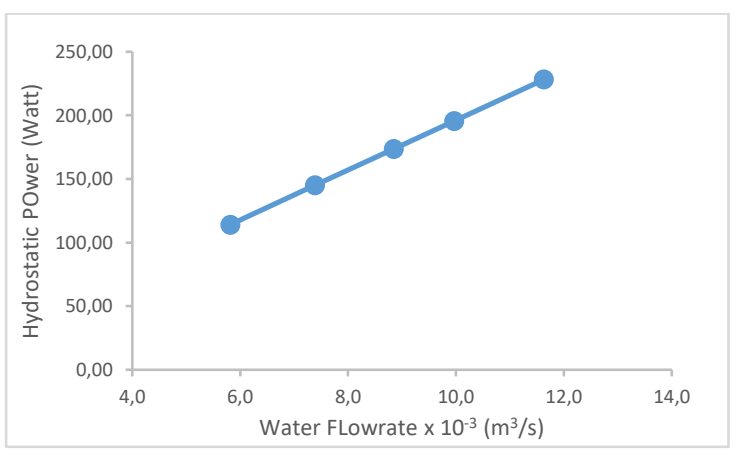

Figure 5. Relationship of water power with discharge

As shown in Figure 5 is the relationship between water power and discharge shows the highest water hydrostatic power at a variety of water flow discharge of $11.61 / \mathrm{s}$ which is 228.17 Watts. Whereas for the lowest water hydrostatic power value is obtained in the variation of water flow rate of $5.61 / \mathrm{s}$ which is 114.09 Watts. Hydrostatics power test results indicate that the greater the discharge rate of the water flow, the greater the hydrostatic power of the water. The value of water power is influenced by several factors: water flow $(\mathrm{Q})$, water density $(\rho)$, gravity (g), and waterfall (h). in this study the parameters other than the water flow discharge are equalized so that the water's Prostatic power is affected by the amount of water flow.

\section{Electrical Power}

The electric power of the generator is the amount of energy produced by the generator due to turbine rotation. The value of electrical power is obtained by multiplying the voltage value and the current strength generated by the generator. Electrical voltage and electric current are obtained from reading the multimeter. Multimeters are installed in series to get the electric current value (A), while to get the voltage value $(\mathrm{V})$, the multimeter is installed in parallel



Figure 6. Voltage relationship with water flow discharge on blade slope variation.
Figure 6. Shows the connection relationship with the flow rate of the water in the blade slope variation. The value of the target is increased along with the increase in fluid flow. The maximum voltage value is obtained at $11.61 / \mathrm{s}$ of fluid flow. Increasing the capacity of water that enters the turbine, the greater the cross-sectional area of the water through which the turbine will flow, so the turbine rotational speed is higher[8]. The higher the rotational speed, the higher the voltage generated by the generator.

The blade angle that produces a maximum stress at a slope of $30 \mathrm{o}$ of water flow rate $11.61 / \mathrm{s}$ with a voltage value of $101 \mathrm{~V}$. The angle of the blade causes a large flow of water that collides the blade is not fully about the blade so that the converted water power is not maximal. Whereas for the small blade angle, the area of the water output is smaller so that it allows the blade section outlet to occur at a higher velocity resulting in a large friction loss[9].



Figure 7. Relationship of current strength with water flow discharge on blade slope variation.

Figure 7 shows the relationship of current strength with fluid flow discharge on the variation of the turbine blade angle obtained the maximum current strength value obtained on the variation of the blade slope of $30^{\circ}$ and the flow rate of $11.61 / \mathrm{s}$ with a current strength of $0.32 \mathrm{~A}$. while for the value the lowest current strength is obtained at a slope of $75^{\circ}$ and the flow rate of water is $5.81 / \mathrm{s}$ with a value of $14 \mathrm{~V}$ and $0.06 \mathrm{~A}$. Increasing the flow rate causes the current strength to increase. The greater the fluid flow discharge, the greater the rotation of the shaft, with increasing turbine shaft rotation, the braking force required is also greater so that it will be proportional to the increased torque[10]. The greater the torque value of the turbine, the turbine's ability to rotate the generator also increases so that the generator rotation increases. The greater the generator rotation, the greater the current value generated is also greater. 


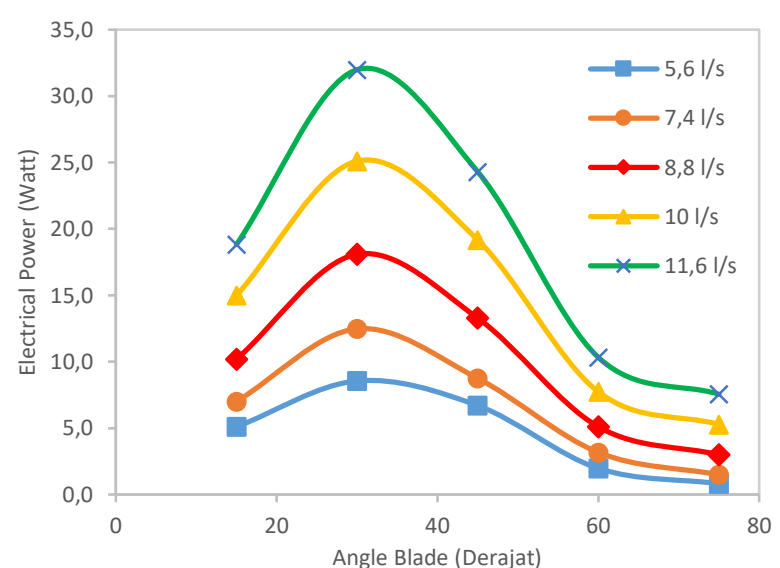

Figure 8. Relationship of electric power with blade slope to variations in water flow discharge.

Figure 8. Shows the relationship of electrical power with blade slope on the variation of water flow discharge the highest electrical power value obtained in the blade slope variation of $30 \mathrm{o}$ and water flow rate of $11.61 / \mathrm{s}$ with an electric power value of 32 Watt. Whereas the lowest rotational speed value was obtained in 750 blade slope variation and $5.81 / \mathrm{s}$ water flow rate of 0.8 Watts. The value of the electric power is influenced by the value of the voltage and current strength.

\section{CONCLUSION}

Based on observations on the slope test of the turbine blade propeller that has been done to determine the effect of the angle of the turbine on the mechanical and electrical power produced. From the results of these tests can be concluded. The highest electrical power value is obtained at a slope variation of $30^{\circ}$ at 32 watts due to the influence of the shaft rotation on the generator rotation and the ability of the blade to change the flow velocity. The blade angle affects the results of generator testing, because the blade angle will affect the axial force that affects the turbine. A large blade angle causes the water flow that collides with the blade is not completely about the blade so that the connected water power is not maximal. Whereas for the small blade angle, the area of the water output is smaller so that it allows the blade outlet section to flow at a higher speed resulting in large friction losses.

\section{REFERENCES}

[1] T. Watiningsih, "Independent electrical energy environment-friendly," Teolodia, vol. 14, no. 1-2, 2013.

[2] H. Zainuddin, M. S. Yahaya, J. M. Lazi, M. F. M. Basar, and Z. Ibrahim, "Design and Development of Pico-hydro Generation System for Energy Storage Using

Consuming Water Distributed to Houses," Eng. Technol., vol. 35, pp. 154-159, 2009.

[3]

[9] T. Shantika and M. Ridwan, "The customization of hydropower generator to provide 100 watts of small-scale electricity supplies," J. Ind. Res., vol. 7, no. 137-146, 2013.

[10] S. J. Williamson, B. H. Stark, and J. D. Booker, "Low head pico hydro turbine selection using a multi-criteria analysis," Renew. Energy, vol. 61, pp. 43-50, 2014.
B. P. Ho-yan, "Design of a Low Head Pico Hydro Turbine for Rural Electrification in J. Susanto and S. Stamp, "Local installation methods for low head pico-hydropower in the Lao PDR," Renew. Energy, vol. 44, pp. 439-447, 2012. Chen, H. Wang, and J. Yan, "Numerical prediction of pressure pulsation for a low Energy, vol. 89, pp. 730-738, 2015. thermodynamics of turbomachinery. Butterworth-Heinemann, 2013.

Himawanto and D. D. D. P. Tjahjana Curvature Blade Impeller Pump as Turbine Picohydro," AIP Conf. Proc., vol. 30008, 2017.

and H. M. Ramos, "Experimental characterization of a five blade tubular peller turbine for pipe inline installation," Renew. Energy, vol. 95, pp. 356-366, 2016. 